San Jose State University

SJSU ScholarWorks

Mineta Transportation Institute Publications

4-2020

\title{
Evaluating Crowdsourcing as a VMT Reduction Tool to Support Smart Cities Initiatives
}

Shailesh Chandra

California State University, Long Beach

Rutviz Vyas

California State University, Long Beach

Ravi Mazin

California State University, Long Beach

Follow this and additional works at: https://scholarworks.sjsu.edu/mti_publications

Part of the Transportation Engineering Commons

\section{Recommended Citation}

Shailesh Chandra, Rutviz Vyas, and Ravi Mazin. "Evaluating Crowdsourcing as a VMT Reduction Tool to Support Smart Cities Initiatives" Mineta Transportation Institute Publications (2020). https://doi.org/ 10.31979/mti.2020.1930

This Report is brought to you for free and open access by SJSU ScholarWorks. It has been accepted for inclusion in Mineta Transportation Institute Publications by an authorized administrator of SJSU ScholarWorks. For more information, please contact scholarworks@sjsu.edu. 


\section{SJSU

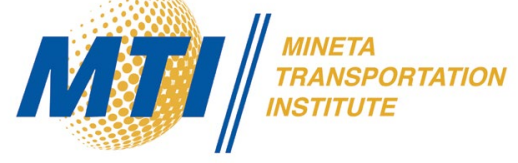

Evaluating Crowdsourcing as a VMT Reduction Tool to Support Smart Cities Initiatives

Shailesh Chandra, $\mathrm{PhD}$

Rutviz Vyas

Ravi Mazin

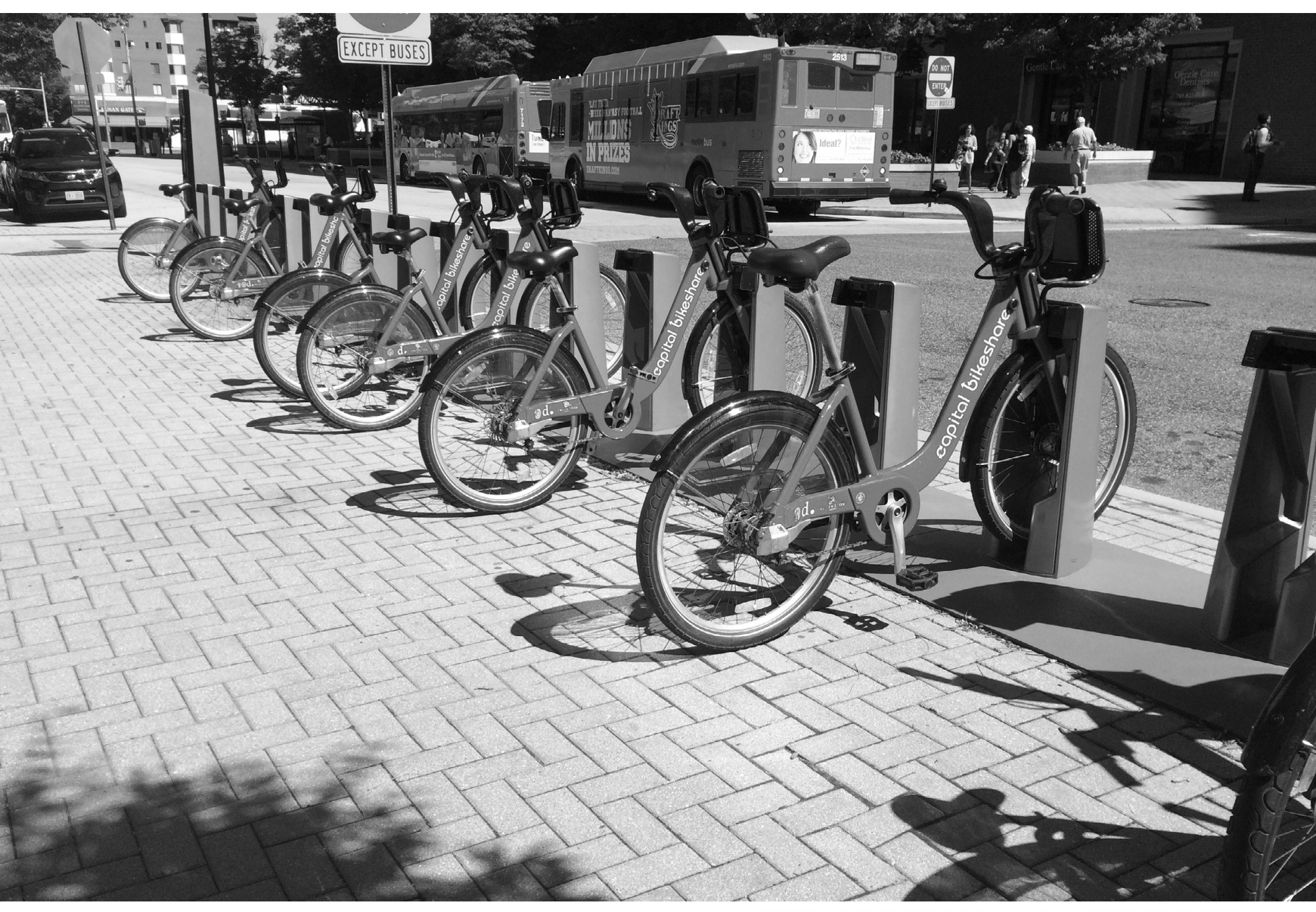

Csutc California State University

CALIFORNIA STATE UNIVERSITY LONG BEACH 


\section{MINETA TRANSPORTATION INSTITUTE}

Founded in 199I, the Mineta Transportation Institute (MTI), an organized research and training unit in partnership with the Lucas College and Graduate School of Business at San José State University (SJSU), increases mobility for all by improving the safety, efficiency, accessibility, and convenience of our nation's transportation system. Through research, education, workforce development, and technology transfer, we help create a connected world. MTI leads the four-university. MTI leads the four-university California State University Transportation Consortium funded by the State of California through Senate Bill I.

MTl's transportation policy work is centered on three primary responsibilities:

\section{Research}

MTI works to provide policy-oriented research for all levels of government and the private sector to foster the development of optimum surface transportation systems. Research areas include: bicycle and pedestrian issues; financing public and private sector transportation improvements; intermodal connectivity and integration; safety and security of transportation systems; sustainability of transportation systems; transportation / land use / environment; and transportation planning and policy development. Certified Research Associates conduct the research. Certification requires an advanced degree, generally a Ph.D., a record of academic publications, and professional references. Research projects culminate in a peer-reviewed publication, available on TransWeb, the MTI website (http://transweb.sjsu.edu).

\section{Education}

The Institute supports education programs for students seeking a career in the development and operation of surface transportation systems. MTI, through San José State University, offers an AACSBaccredited Master of Science in Transportation Management and graduate certificates in Transportation Management, Transportation Security, and High-Speed Rail Management that serve to prepare the nation's transportation managers for the 2 I st century. With the active assistance of the California Department ofTransportation (Caltrans), MTI delivers its classes over a state-of-the-art videoconference network throughout the state of California and via webcasting beyond, allowing working transportation professionals to pursue an advanced degree regardless of their location. To meet the needs of employers seeking a diverse workforce, MTl's education program promotes enrollment to under-represented groups.

\section{Information and Technology Transfer}

MTI utilizes a diverse array of dissemination methods and media to ensure research results reach those responsible for managing change. These methods include publication, seminars, workshops, websites, social media, webinars, and other technology transfer mechanisms. Additionally, MTI promotes the availability of completed research to professional organizations and journals and works to integrate the research findings into the graduate education program. MTl's extensive collection of transportation- related publications is integrated into San José State University's world-class Martin Luther King, Jr. Library.

\section{Disclaimer}

The contents of this report reflect the views of the authors, who are responsible for the facts and accuracy of the information presented herein. This document is disseminated in the interest of information exchange. The report is funded, partially or entirely, by a grant from the State of California. This report does not necessarily reflect the official views or policies of the State of California or the Mineta Transportation Institute, who assume no liability for the contents or use thereof. This report does not constitute a standard specification, design standard, or regulation. 
REPORT 20-14

\title{
EVALUATING CROWDSOURCING AS A VMT REDUCTION TOOL TO SUPPORT SMART CITIES INITIATIVES
}

\author{
Shailesh Chandra, PhD \\ Rutviz Vyas \\ Ravi Mazin
}

April 2020

A publication of

Mineta Transportation Institute

Created by Congress in 1991

College of Business

San José State University

San José, CA 95192-0219 


\section{TECHNICAL REPORT DOCUMENTATION PAGE}

1. Report No. 20-14

4. Title and Subtitle

Evaluating Crowdsourcing as a VMT Reduction Tool to Support Smart Cities Initiatives

7. Authors

Shailesh Chandra, PhD

Rutviz Vyas

Ravi Mazin

9. Performing Organization Name and Address

Mineta Transportation Institute

College of Business

San José State University

San José, CA 95192-0219

12. Sponsoring Agency Name and Address

State of California SB1 2017/2018

Trustees of the California State

University

Sponsored Programs Administration

401 Golden Shore, 5th Floor

Long Beach, CA 90802
2. Government Accession No.

3. Recipient's Catalog No.

5. Report Date

April 2020

6. Performing Organization Code

8. Performing Organization Report

CA-MTI-1930

10. Work Unit No.

11. Contract or Grant No. ZSB12017-SJAUX

13. Type of Report and Period Covered Final Report

14. Sponsoring Agency Code

15. Supplemental Notes

DOI: $10.31979 / \mathrm{mti} .2020 .1930$

\section{Abstract}

Vehicle miles traveled (VMT) is an indicator of vehicular emissions, which impacts climate change. Various stakeholders aim at reducing VMT to cause reductions in emissions. This research explores the use of crowdsourcing in supporting the efforts of the stakeholders in reducing VMT among college students at California State University Long Beach. Crowdsourcing is emerging as a very promising tool in finding solutions to problems otherwise impossible to solve without a collective human intelligence. A smartphone application is developed to collect travel data and behavior of 55 college students as participants. The behavior is tracked after providing advance information on parking availability on the university campus. It is observed that VMT reductions occur from Monday, Wednesday, and Thursday with car users and Monday through Thursday with transit bus users. The largest reduction of $4 \%$ occurs with car usage on Thursday. On the same day, the highest reduction in VMT of $5 \%$ occurs with bus usage. Thus, crowdsourcing information on campus parking showed that VMT reduction is effective with the small number of participants involved in this pilot study.

\section{Key Words}

Vehicle miles traveled, crowdsourcing, smartphone, driving, ridership

\section{Distribution Statement}

No restrictions. This document is available to the public through The National Technical Information Service, Springfield, VA 22161
19. Security Classif. (of this report) Unclassified
20. Security Classif. (of this page) Unclassified
21. No. of Pages

17
22. Price 


\title{
Copyright $\odot 2020$ \\ by Mineta Transportation Institute \\ All rights reserved
}

\section{DOI: \\ 10.31979/mti.2020.1930}

\author{
Mineta Transportation Institute \\ College of Business \\ San José State University \\ San José, CA 95192-0219 \\ Tel: (408) 924-7560 \\ Fax: (408) 924-7565 \\ Email: mineta-institute@sjsu.edu
}

transweb.sjsu.edu 


\section{ACKNOWLEDGMENTS}

The authors thank Editing Press, for editorial services, as well as MTI staff, including Executive Director Karen Philbrick, PhD; Deputy Executive Director Hilary Nixon, PhD; Graphic Designer Alverina Eka Weinardy; and Executive Administrative Assistant Jill Carter. 


\section{TABLE OF CONTENTS}

$\begin{array}{lr}\text { Executive Summary } & 1\end{array}$

I. Introduction and Background 3

$\begin{array}{ll}\text { II. Methodology } & 5\end{array}$

$\begin{array}{ll}\text { III. Data Collection } & 6\end{array}$

$\begin{array}{lr}\text { IV. Analysis and Results } & 9\end{array}$

$\begin{array}{ll}\text { V. Concluding Remarks } & 11\end{array}$

$\begin{array}{ll}\text { VI. Policy/Practice Recommendations } & 12\end{array}$

$\begin{array}{ll}\text { Abbreviations and Acronyms } & 13\end{array}$

$\begin{array}{lr}\text { Bibliography } & 14\end{array}$

$\begin{array}{ll}\text { About the Authors } & 16\end{array}$

$\begin{array}{ll}\text { Peer Review } & 17\end{array}$ 


\section{LIST OF FIGURES}

1. Map of CSULB Parking Lots $\quad 7$

2. Smartphone Application User Interface $\quad 8$ 


\section{LIST OF TABLES}

1. Mode Share 'Before' Using the Smartphone Application 10

2. Mode Share 'After' Using the Smartphone Application 10

$\begin{array}{ll}\text { 3. Percentage VMT Reduction } & 10\end{array}$ 


\section{EXECUTIVE SUMMARY}

Transportation activity is an indicator of the economic growth and prosperity of a city. Millions of consumer needs in society are fulfilled by transportation through various modes, such as passenger cars, transit buses, and rails. In order to meet these needs, vehicles that rely on fossil fuels are commonly utilized, thereby causing an increase in emissions and air pollution. These emissions are very commonly observed in concentrated amounts, especially at large crowd gatherings and locations that experience high vehicular traffic volumes. Examples of such locations are parking lots of high-density commercial, residential, and industrial facilities. A significant amount of emissions emanates from such parking lots when drivers are driving around to find parking spaces. However, due to a lack of information on available spots, unnecessary driving is quite common in such large parking lots. With a lack of information on parking, drivers compete for space at these high-traffic-volume lots, especially during peak periods of occupancies. Thus, a large crowd of uninformed drivers adds tremendous amounts of vehicular emissions at these lots. This research tests the hypothesis that the crowd itself can be used to mitigate emissions generated at parking lots. In addition, the mitigation can become very effective with advance information relayed on parking occupancies to drivers.

In this research, crowdsourcing is used as a tool to test the hypothesis expressed above. Crowdsourcing refers to the technique of gathering opinions and information from the crowd. With this approach, solutions are found to problems that are otherwise hard or impossible to solve. Solutions are achieved by using the combined intelligence of the crowd to make a much more informed decision; information can be relayed back to the other members of the crowd to further influence decisions. Applications of the crowdsourcing technique are found in Google Maps and Bing Maps. These applications derive travel speed information from drivers, and the information collected is used to provide advisory information on optimal paths to other drivers stuck in traffic.

In fulfilling the objectives of this research, parking information across the campus parking lots of CSULB was collected. The parking availabilities were collected on random days of the week from Monday to Friday and at random times between 8 am to 7 pm during one month of Fall 2019. The goal was to achieve an estimate of parking availabilities from 8 am to $7 \mathrm{pm}$ on a typical day of the week, Monday through Friday. This aim was successfully achieved with the random data collection approach. Subsequently, the data collected were considered as master data and fed into a smartphone-based application developed for the study.

In a simultaneous effort in this research, there were 55 student volunteers selected as participants from the College of Engineering at California State University Long Beach. The participants were selected in order to study the effect of advance availability information on parking status on campus and subsequent impact on their mode choice behaviors. This part of the research effort was carried out over a two-month period. During the first one month, data collection consisted of determining the prevailing modes and time of travel of the participants using the app. This was executed without enabling the parking information in the app. At the commencement of this part of the data collection effort, the parking information was enabled for the next one-month study. Users were asked to evaluate parking availability using the app before heading to the campus. The application was very intuitive, as shown 
in the screenshot of the image below-it also provided advance information on parking availability at campus to app users.

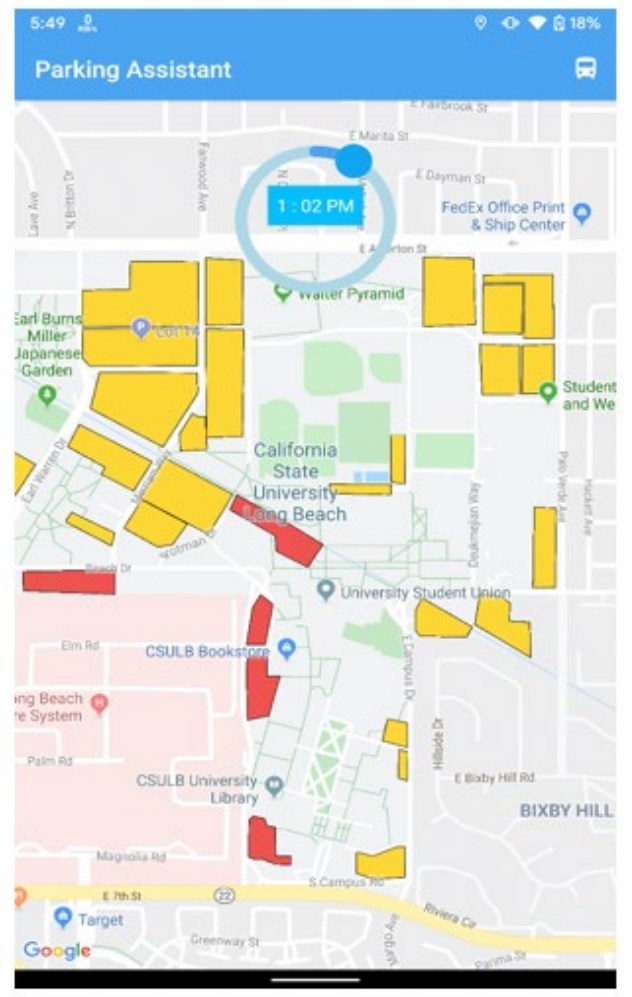

(a) Parking occupancy at 1:02 PM

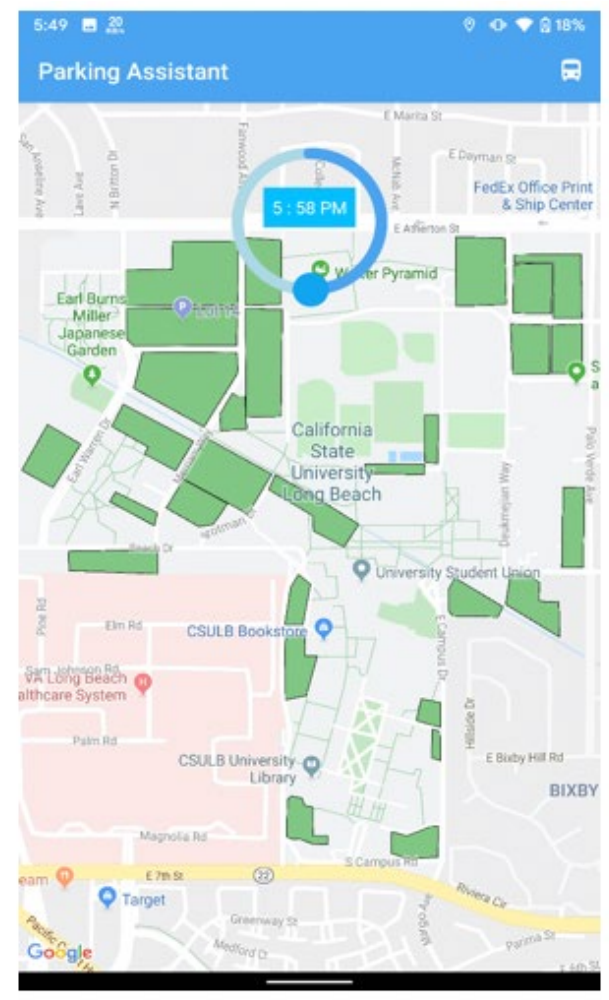

(b) Parking occupancy at 5:58 PM

The location of each participant was tracked during their travel to the CSULB campus. If the mode choice was a car, ease of parking (consisting of drive times in a lot) was recordedwhich was ultimately used to update the master file on the availability status of parking in real time. Thus, the master file on travel data was made dynamic.

Across different modes, car usage among the participants was found to be the highest, followed by transit (bus) and other modes used to reach the campus. An analysis carried out for 'before' and 'after' introducing the smartphone application among participants showed that car driving to campus reduced and there was a subsequent increase in transit usage. This finding indicates that providing advance campus parking status to the participants might have played a role in their mode choice decisions. Overall, there was a net percentage reduction in vehicle miles traveled (VMT).

This research shows a very promising facet of crowdsourcing's role in smart city initiatives through illustrating how it may promote VMT reductions in a community. The research methodology could be replicated on a larger scale to include an increased number of participants who would contribute to the research findings. Thus, advance traveler information on real-time parking availability for drivers heading to crowded gatherings could cause greater VMT reductions and increased usage of alternate active transportation modes in a smart city setting. 


\section{INTRODUCTION AND BACKGROUND}

Increases in vehicle miles traveled (VMT) are detrimental to building environmentally sustainable and safer communities. While environmental sustainability is impacted by an increase in emissions, communities are rendered unsafe when VMT increases, leading to increases in vulnerability to crashes (Dogan et al., 2011). In addition to these issues, high VMT means reduced reliance and missed opportunity to use public transportation systems. Use of active transportation modes such as bicycling and walking, which are considered critical for the success of "complete streets" (Stevens, 2017), is also reduced, since these modes are important parts of a trip chain of public transport (Giles-Corti et al., 2010). VMT is inherently tied to the extent of emission levels which impacts the economic vitality of a city. For example, in Los Angeles, which is a dense and highly populated city of California, searching for parking space in lots causes a significant economic burden to drivers, adds to VMT, and triggers health-related effects due to pollution to nearby communities (METRO, 2018). VMT reduction is also critical in addressing the social equity and climate goals of such heavily populated and congested cities. Thus, in order to build cities that are smart and safer, VMT reduction is a must.

Innovative methods need to be deployed to bring about VMT reductions, and these methods include mode shift to walking and bicycling, which are sustainable modes of transportation. However, a lack of data availability on the problems faced by such users of sustainable modes prevents the implementation of measures that can be used for VMT reductions. In this respect, crowdsourcing is emerging as a powerful tool to provide possible solutions to problems that are traditionally expensive to solve due to limitations in data availability (Chatzimilioudis et al., 2012; Chandra et al., 2019). Crowdsourcing refers to the technique of gathering opinions and information from the crowd to "find solutions which otherwise would be hard or impossible to resolve" (Ali et al., 2012). Therefore, when used effectively, crowdsourcing can use the public's intelligence and skills to solve complex issues (Misra et al., 2014). Social media platforms such as Twitter, Facebook, and so on serve as examples of crowdsourcing (Alvaro et al., 2015), and their utility can be found in disaster relief operations or other situations in which traditional methods are unavailable or not viable (Gao et al., 2011).

In transportation, although there has been some isolated (but important) use of crowdsourcing, there is still its enormous potential that needs to be thoroughly studied. Some potential applications of crowdsourcing are already being explored, though their utility has yet to be explicitly demonstrated, such as the application of crowdsourcing in obtaining real-time information on public transit, traffic delays, parking conditions, and so on (Misra et al., 2014).

Crowdsourcing can be used to determine human behavior on several transportationrelated issues, particularly for mode choice decisions and in estimating VMT reduction, with advantages over existing traditional stated preference and revealed preference surveys (Heilig et al., 2017). Inherent complexities due to the static nature of surveys and interviews in capturing human behavior and expectations make data collection through traditional surveys less than ideal as a method for understanding drivers' mode choice in real-time. Most of the survey-based research outcomes are limited to providing insights at the disaggregated individual level, which may not reflect correlation in opinions due to social behavior at the 
group scale or influence mode shift behaviors at the individual level (Eftekhar et al., 2013).

Based on the literature survey carried out, there are few limited studies that illustrate use of crowdsourcing in understanding and influencing the travel behavior of drivers-such as a pilot study conducted by Iniguez et al. (2018) on college students. However, there were no direct implications on VMT reduction deduced from the study. Although the information obtained through surveys is very useful for understanding transportation problems that exist locally or within the area surveyed, the policy implications and impacts can be better justified empirically at the aggregate level. Most studies conducted in this aspect report the status quo of travel patterns but do not include the influence of the crowd on minimizing VMT. This is primarily due to lack of models that can capture the crowdsourcing element into VMT reduction strategies. A suitable choice of modeling technique can be deployed to understand the determinants that govern the complex human behavior of mode choice from among a set of available options and variables through a real-time information sharing system. Crowdsourcing can help in developing an in-depth understanding of both qualitative and quantitative aspects of people's perceptions, attitudes, and behaviors toward choosing between a private car and public transport-this is due to inherent nature of decisions that are undertaken by crowd constituting the technique of crowdsourcing. While qualitative methods directly allow assessment and explanations of a transport user's behavior and attitudes, quantitative methods draw implications and attitudes from a traveler's mode choice based on statistical data analyses (Beirão and Cabral, 2007). The larger the number of individuals in the crowd, the better justifiable are the policy decisions. Crowdsourcing can help express both qualitative and quantitative aspects of the mode choice decision making of drivers in one single policy implication (Iniguez et al., 2018). 


\section{METHODOLOGY}

Crowdsourcing has been widely used for trip management and routing decisions, and particularly for smartphone and web-based applications: one such example is Google Maps (2018). However, the knowledge of the impact crowdsourcing can have on human behavior in transportation is very limited. While Google Maps is a very useful application for navigational purposes, transportation experts argue that such apps often guide cars off the freeway onto city streets, making traffic conditions and VMT worse on local streets (Berkeley News, 2018). Thus, there is limited knowledge of such apps and their impact on VMT reduction, and any subsequent mode shifts that might occur with app-based route guidance need investigation. (The data available from Google Maps are also limited and available to the public for a fee depending on the size of the data needed.) In addition, pilot studies to test impacts of certain specific measures on travel behavior cannot be successfully conducted due to privacy concerns of participants' location and travel information being shared by a third party like Google. In practice, crowdsourcing is being used in states like Minnesota by Cyclopath, a geo-wiki, to track the quality of bike lanes and trails (Cyclopath, 2016). However, very few studies document the impact crowdsourced information can have on travel behavior. This was the primary motivation for building and using a customized app in this research.

The methodology of data collected through the use of the crowdsourcing app allows a user to see the mode choice made by other app users. This potentially influences the mode choice decisions of all the app research participants. The specific purpose of the app was to provide feeds on traffic information, parking, and availability of alternate modes to capture any changes in VMT in a crowdsourcing environment. To the best of our knowledge, this pilot study, under these settings, has not been conducted in research assessing mode choice decisions. 


\section{DATA COLLECTION}

In fulfilling the objectives of this research, parking information across the campus parking lots of CSULB was collected. The parking availabilities were collected on random days of the week from Monday to Friday and at random times between 8 am to $7 \mathrm{pm}$ during the first 30 days of Fall 2019. The goal was to achieve an estimate of parking availabilities from 8 am to $7 \mathrm{pm}$ on a typical day of the week, Monday through Friday. This was successfully achieved with the random data collection approach. The parking information was compiled in terms of percent of occupancy during the time of data collection. On-site parking data were collected for the major parking lots used by the students on the campus. The image in Figure 1 shows the information on CSULB's parking lots. These lots cater to the parking needs of the majority of CSULB's students. Subsequently, the data collected were considered as master data and fed into a smartphone-based application developed on the Android platform for the study (see Figure 2).

The application was very intuitive, as shown in the screenshot of the image shown in Figure 2. The app user could set the time at which the parking information was sought. This was made accessible using the app interface that showed the variation in parking availability in real time as well as for the coming 24 -hour time period. This was useful for informing the app users of the parking scenario on campus before they headed to the campus. The visual color schemes across the parking lots determined whether the parking lot was full, partially full, or completely occupied. For example, a complete red shade over a parking lot indicated that the parking lot was full, while the green shade showed that there were spaces available at the lots. A yellow shade indicated that the parking lot was partially full. In the images shown in Figure 2a, at 1:02 pm some parking lots are full, while in Figure $2 \mathrm{~b}$, at 5:58 pm all the parking lots have parking space available.

The smartphone app was distributed to many students from the college of engineering. The students selected for distribution of the app had access to multiple modes of transportation which they could use to arrive the campus during any weekday. However, a significant number of users failed to download the application and give it permission to detect their location. (The participants were asked to enable their location during app download and installation on their smartphones.) There were finally 55 student volunteers selected as research participants in this research who didn't mind tracking their location. These participants were selected to study the effect of advance information availability on parking status on campus and the subsequent impact on their mode choice behaviors. The study was carried out over a period of two months during Fall 2019 and included only Mondays to Fridays of the months of September-November.

During the first month of the data collection, the use of prevailing modes and travel times of the participants to the CSULB campus were determined. The information was collected using the app distributed at the beginning of the first month of the data collection effort. 


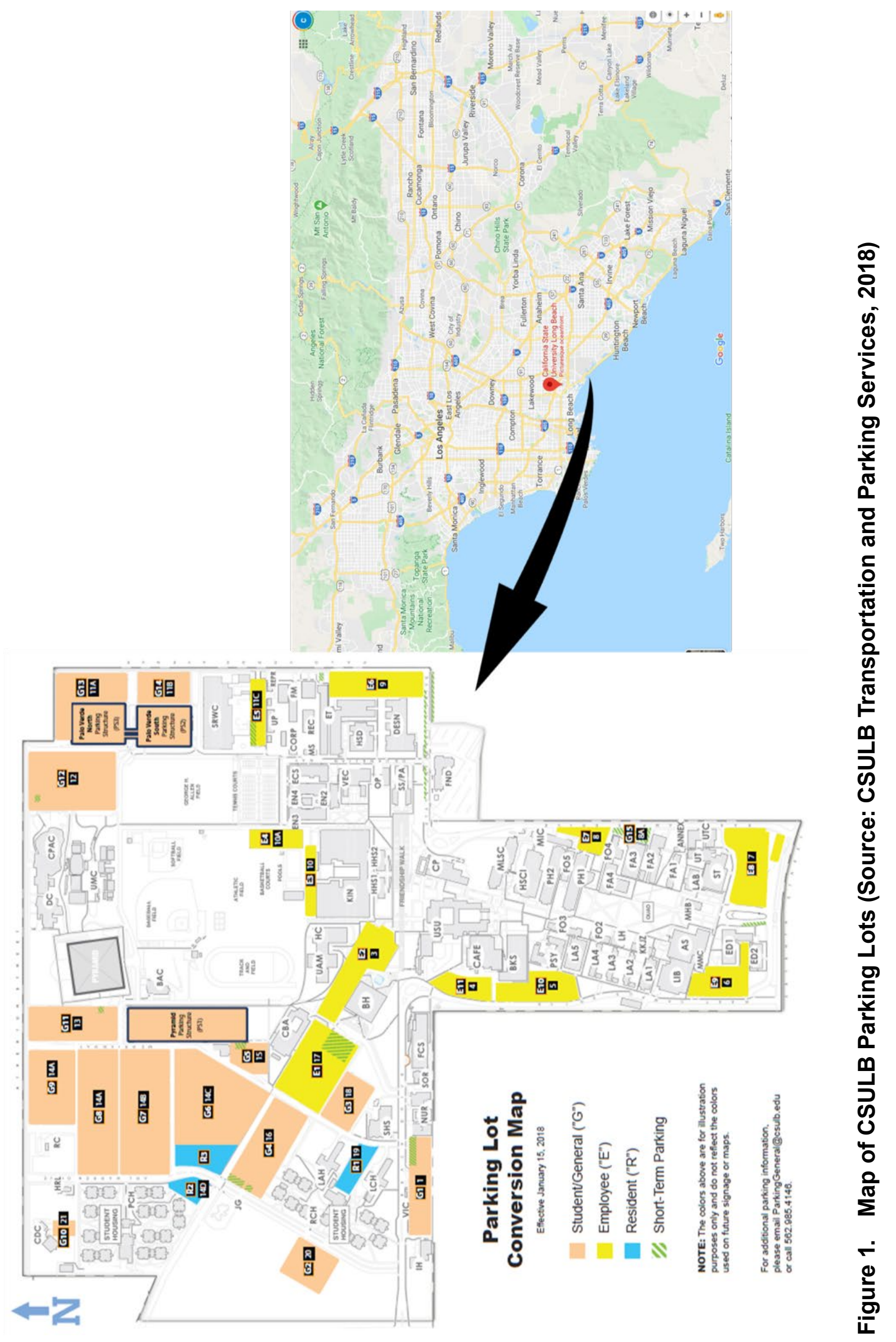



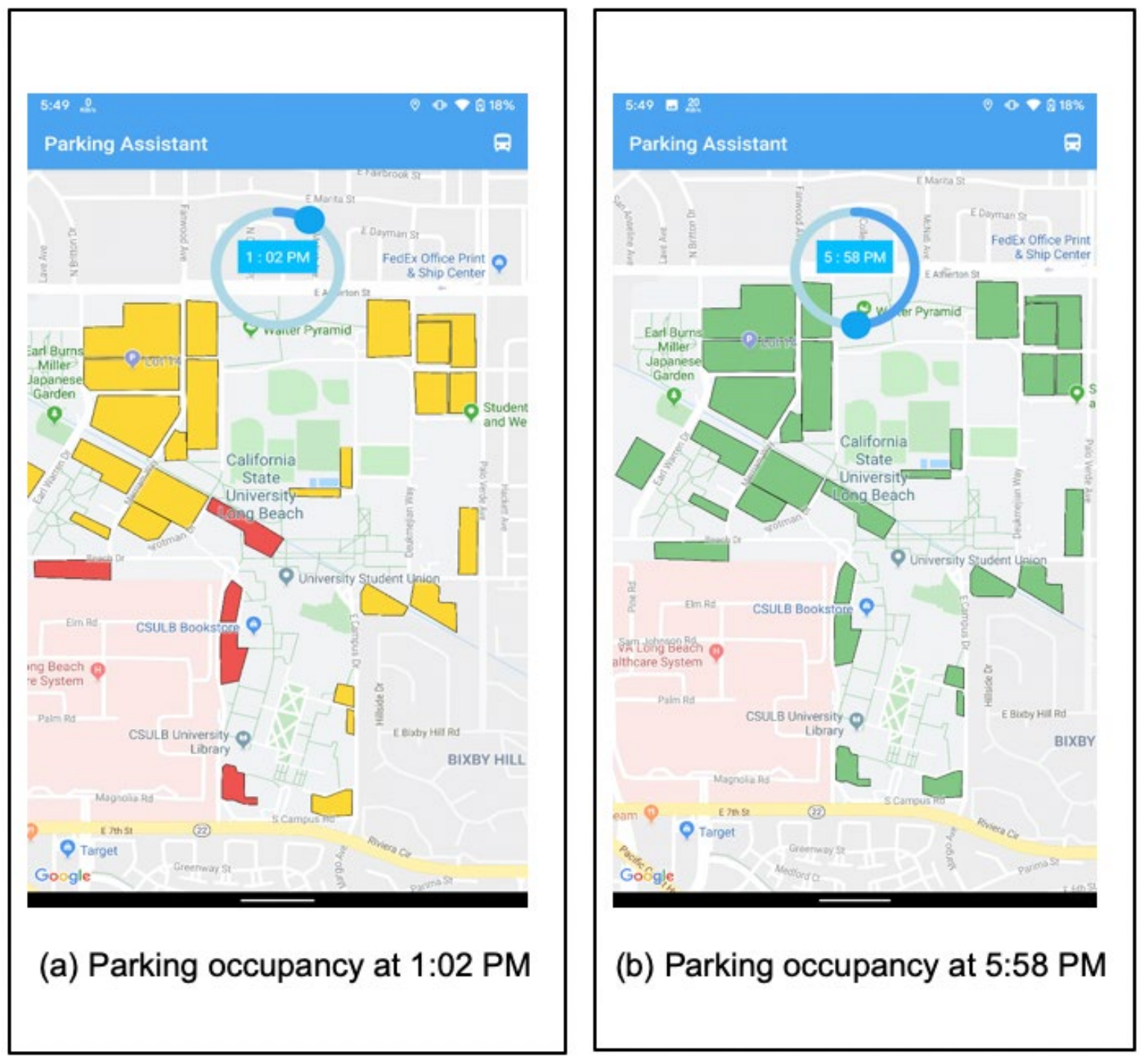

Figure 2. Smartphone Application User Interface

At the commencement of the first one month of the data collection effort, the app was used to collect travel time information from the users. The app did not provide the parking information to the user. The purpose of this effort was to collect unbiased travel time and mode choice information from the research participants. In the subsequent phase, the parking information was made available for the users. In this phase, the app users were asked to evaluate the parking availability before heading to the campus.

Every Monday, the researchers reminded the participants to use the application just to make sure they checked the app when deciding to travel to the campus. The research team gathered users' daily travel data and stored them on the firebase (an online database by Google). The data from 55 people for two months yielded around 3300 entries in the database. 


\section{ANALYSIS AND RESULTS}

One the main concerns during the data collection effort was related to the users' privacy regarding their location during the use of the app. The location information was protected by limiting the recording of the information on the origin and the destination of the users only to instances wherein the trip originated from the home and ended at the campus location as the destination. The location was updated every second and the information was available only at the user's end at his/her smartphone device. No information on travel gathered through the app was sent to the server. Using this approach, the privacy of the user was never compromised.

The available sources of information collected through the app were speed and the distance covered by the user while using the app-information which was eventually used to obtain the travel time information. Since the researchers were also obtaining the location of the app user, metrics used were the speed, distance from CSULB, and the number of stops to determine the mode of transport used. The following formula was used to decide the mode of transport:

Bus: the user's location ended at a bus stop close to the CSULB campus. The speed reduced to walking speed immediately after alighting from the bus.

Car: the user's location ended within a parking lot location at CSULB campus. The speed reduced to walking speed immediately after alighting from the car.

Bicycling, walking, or some other coasting device: If the user's travel speed was less than 14 miles per hour throughout the journey to CSULB, then the mode used is bicycling, walking or some other coasting device.

The computing power of the smartphone was used to determine whether the person was travelling by car, bus, or another mode of transport.

The app provided information on parking space availability on the campus. This was done by providing information on percentage availability of parking space at each lot. Based on this information, the app user could determine, if they drove to campus, whether they would be able to find a parking space. If they determined that they would not be able to find parking, then they could use some other mode of transport such as transit, and this was recorded as VMT reduction. Alternatively, the user could also decide to travel at another time (more than an hour later) using the same mode. It was noted that the usual departure time differed significantly when compared to the usual departure times noted during the first one month of the data collection exercise. All the instances-whenever the app was opened or accessed and whether travel to CSULB occurred-were recorded through the app.

Researchers further classified the first one month of data collection effort as the 'before' period (before providing app-based parking information to the users) and the next one month of data collection effort as the 'after' period (after providing the parking information to the users). Thus, the analysis is carried out by comparing the 'before' and 'after' travel behaviors of the app users - with the information on parking being crowdsourced to the users. 
In this research, it was considered that an increase (or decrease) in the use of bus transit would indicate a decrease (or increase) in equivalent private car usage. This would subsequently translate to a decrease (or increase) in passenger car VMT.

Tables 1 and 2 show the variation in average transportation mode shares for each weekday across the modes of car, transit bus, and alternative modes such as bicycling, walking, or coasting devices.

Table 3 shows the reduction in VMT resulting from a decrease in percentage of average mode share from the 'before' to the 'after' scenarios. It is observed that VMT reductions occur on Monday, Wednesday, and Thursday with car users and Monday through Thursday with transit bus users. The largest reduction of $4 \%$ occurred with car on Thursday. On the same day, the highest reduction in VMT of $5 \%$ occurs with bus usage. Thus, crowdsourcing information on campus parking showed that VMT reduction is effective with the small number of participants involved in this pilot study.

Table 1. Mode Share 'Before' Using the Smartphone Application

\begin{tabular}{cccc}
\hline & \multicolumn{3}{c}{ Mode Share } \\
\cline { 2 - 4 } Day of the Week & Car & Bus & Bicycling, walking, or coasting deices \\
\hline Monday & $65 \%$ & $34 \%$ & $1 \%$ \\
Tuesday & $62 \%$ & $37 \%$ & $1 \%$ \\
Wednesday & $61 \%$ & $39 \%$ & 0 \\
Thursday & $66 \%$ & $33 \%$ & $1 \%$ \\
Friday & $68 \%$ & $32 \%$ & 0 \\
\hline
\end{tabular}

Table 2. Mode Share 'After' Using the Smartphone Application

\begin{tabular}{cccc}
\hline & \multicolumn{3}{c}{ Mode Share } \\
\cline { 2 - 4 } Day of the Week & Car & Bus & Bicycling, walking, or coasting deices \\
\hline Monday & $62 \%$ & $36 \%$ & $2 \%$ \\
Tuesday & $62 \%$ & $38 \%$ & $0 \%$ \\
Wednesday & $59 \%$ & $40 \%$ & $1 \%$ \\
Thursday & $62 \%$ & $38 \%$ & 0 \\
Friday & $68 \%$ & $32 \%$ & 0 \\
\hline
\end{tabular}

Table 3. Percentage VMT Reduction

\begin{tabular}{ccc}
\hline Day of the Week & VMT reduction with car* & VMT reduction with bus $^{*}$ \\
\hline Monday & $3 \%$ & $2 \%$ \\
Tuesday & $0 \%$ & $1 \%$ \\
Wednesday & $2 \%$ & $1 \%$ \\
Thursday & $4 \%$ & $5 \%$ \\
Friday & $0 \%$ & 0 \\
\hline
\end{tabular}

* \% mode share in Table 2 minus $\%$ mode share in Table 1 


\section{CONCLUDING REMARKS}

Crowdsourcing is finding widespread applications as a cost-effective technique in fields which require heavy deployment of resources for data collection. To the extent that the number of participating entities enriches the data quality during crowdsourcing, the latter can become one of the best means of achieving accuracy in transportation applications, particularly for travel management and routing decisions. This research fills this gap with a small-scale pilot study using 55 student volunteers as participants from CSULB.

Research findings show that there is an observable reduction in VMT when CSULB's campus parking information is crowdsourced to the research participants. The percentage reduction in VMT occurs in the range of $2-4 \%$. This magnitude of reduction in VMT might not have occurred if the participants were not exposed to the parking situation on the campus before travel. A mode shift from cars to transit was evident with participants who had access to multiple modes for traveling to the campus. However, this might not have been the case had the participant had access to only one mode of transport.

The findings of this research can be further validated by increasing the participant pool in this crowdsourcing exercise. The results will clearly have some very wide-spread implications beyond college settings in popularizing mode shifts to transit and other active transportation modes if appropriate social media channels and information-sharing mechanisms operate through crowdsourcing with transport users. 


\section{POLICY/PRACTICE RECOMMENDATIONS}

This research shows that crowdsourcing can emerge as a very cost-effective method in causing mode shift behavior to active and sustainable modes of transportation. This research could be conducted on a large scale to observe any significant change in driver behaviors and driving habits due to advance sharing of parking information. 


\section{ABBREVIATIONS AND ACRONYMS}

CSULB California State University Long Beach

VMT Vehicle Miles Travelled 


\section{BIBLIOGRAPHY}

Ali, Kashif, Dina Al-Yaseen, Ali Ejaz, Tayyab Javed, and Hossam S. Hassanein. "Crowdits: Crowdsourcing in intelligent transportation systems." In 2012 IEEE Wireless Communications and Networking Conference (WCNC), pp. 3307-3311. IEEE, 2012. https://doi.org/10.1109/WCNC.2012.6214379

Alvaro, Nestor, Mike Conway, Son Doan, Christoph Lofi, John Overington, and Nigel Collier. "Crowdsourcing Twitter annotations to identify first-hand experiences of prescription drug use." Journal of Biomedical Informatics 58 (2015): 280-287. https://doi.org/10.1016/j.jbi.2015.11.004

Beirão, Gabriela, and JA Sarsfield Cabral. "Understanding attitudes towards public transport and private car: A qualitative study." Transport Policy 14, no. 6 (2007): 478-489. https://doi.org/10.1016/j.tranpol.2007.04.009

Berkeley News, "Why traffic apps make congestion worse'-Robert Sanders," accessed on September 22, 2018. http://news. berkeley.edu/story_jump/why-traffic-appsmake-congestion-worse/

Chandra, Shailesh, R. Thirumaleswara Naik, and Jose Jimenez. "Crowdsourcing-based traffic simulation for smart freight mobility." Simulation Modelling Practice and Theory 95 (2019): 1-15. https://doi.org/10.1016/j.simpat.2019.04.004

Chatzimilioudis, Georgios, Andreas Konstantinidis, Christos Laoudias, and Demetrios Zeinalipour-Yazti. "Crowdsourcing with smartphones." IEEE Internet Computing 16, no. 5 (2012): 36-44. https://doi.org/10.1109/MIC.2012.70

Cyclopath, accessed on January 2, 2016. http://cycloplan.cyclopath.org/\#

Dogan, Ebru, Linda Steg, and Patricia Delhomme. "The influence of multiple goals on driving behavior: The case of safety, time saving, and fuel saving." Accident Analysis \& Prevention 43, no. 5 (2011): 1635-1643. https://doi.org/10.1016/j.aap.2011.03.002

Eftekhar, Milad, Yashar Ganjali, and Nick Koudas. "Information cascade at group scale." In Proceedings of the $19^{\text {th }}$ ACM SIGKDD International Conference on Knowledge Discovery and Data Mining, pp. 401-409. ACM, 2013. https://doi. org/10.1145/2487575.2487683

Gao, Huiji, Geoffrey Barbier, and Rebecca Goolsby. "Harnessing the crowdsourcing power of social media for disaster relief." IEEE Intelligent Systems 26, no. 3 (2011): 10-14. https://doi.org/10.1109/MIS.2011.52

Giles-Corti, Billie, Sarah Foster, Trevor Shilton, and Ryan Falconer. "The co-benefits for health of investing in active transportation." New South Wales public health bulletin 21, no. 6 (2010): 122-127. https://doi.org/10.1071/NB10027 
Google Maps, Google Crowdsourcing Projects That Help Us Today - MakeUseOf, accessed on March 22, 2018. https://www.makeuseof.com/tag/7-googlecrowdsourcing-projects-help-us-today/

Heilig, Michael, Nicolai Mallig, Tim Hilgert, Martin Kagerbauer, and Peter Vortisch. "Largescale ap-plication of a combined destination and mode choice model estimated with mixed stated and revealed preference data." Transportation Research Record 2669, no. 1 (2017): 31-40. https://doi.org/10.3141/2669-04

Iniguez, Liliana, Jose Jimenez, and Shailesh Chandra. Investigating Impact of Crowdsourcing on Mode-Shift Behavior of College Students. No. 18-03871. 2018. $97^{\text {th }}$ Annual Meeting of Transportation Research Board, 8-12 January 2018, Washington, D.C.

Metro Magazine, "New study finds parking is the largest cost of driving," METRO, accessed on June 1, 2018. http://www.metro-magazine.com/managementoperations/news/729371/new-study-finds-parking-is-the-largest-cost-of-driving

Misra, Aditi, Aaron Gooze, Kari Watkins, Mariam Asad, and Christopher A. Le Dantec. "Crowdsourcing and its application to transportation data collection and management." Transportation Research Record 2414, no. 1 (2014): 1-8. https://doi. org/10.3141/2414-01

Stevens, Mark R. "Does compact development make people drive less?" Journal of the American Planning Association 83, no. 1 (2017): 7-18. https://doi.org/10.1080/0194 4363.2016.1240044 


\section{ABOUT THE AUTHORS}

\section{SHAILESH CHANDRA}

Dr. Chandra is an Assistant Professor in the Department of Civil Engineering and Construction Engineering Management at California State University Long Beach (CSULB). He obtained his M.S. and Ph.D. in civil engineering from Texas A\&M University in 2009 and 2012, respectively. Dr. Chandra has more than ten years of experience in transportation research focused on first/last mile transport connectivity, urban freight and sustainability. He has been a principal investigator (PI) for several projects funded by the California Department of Transportation (Caltrans) and the United States Department of Transportation (USDOT). Dr. Chandra has also been guiding several graduate and undergraduate students in transportation research at CSULB. Five students have already graduated with M.S. degrees. Currently, he is an advisor to five students who are working on various transportation-related research projects.

\section{RUTVIZ VYAS}

Mr. Rutviz Vyas is a graduate student in the Department of Computer Engineering \& Computer Science at California State University Long Beach (CSULB). Mr. Vyas completed his undergraduate studies in Computer Engineering at Gujarat Technical University, India, in 2018. Mr. Vyas specializes in smartphone application development. His research interests include the application of algorithms and computer programming in transportation engineering and planning.

\section{RAVI MAZIN}

Mr. Ravi Mazin is an undergraduate student in the Department of Civil Engineering \& Construction Engineering Management at California State University Long Beach. His research interests include data collection and analysis pertaining to transportation engineering and planning. 


\section{PEER REVIEW}

San José State University, of the California State University system, and the Mineta Transportation Institute (MTI) Board of Trustees have agreed upon a peer review process required for all research published by MTI. The purpose of the review process is to ensure that the results presented are based upon a professionally acceptable research protocol. 


\author{
Founder, Honorable \\ Norman Mineta (Ex-Officio) \\ Secretary (ret.), \\ US Department of Transportation \\ Chair, \\ Abbas Mohaddes (TE 202I) \\ President \& COO \\ Econolite Group Inc. \\ Vice Chair, \\ Will Kempton (TE 2022) \\ Retired \\ Executive Director, \\ Karen Philbrick, PhD \\ (Ex-Officio) \\ Mineta Transportation Institute \\ San José State University \\ Richard Anderson \\ (Ex-Officio) \\ President \& CEO \\ Amtrak \\ David Castagnetti (TE 202 I) \\ Co-Founder \\ Mehlman Castagnetti \\ Rosen \& Thomas \\ Maria Cino (TE 202 I) \\ Vice President \\ America \& U.S. Government \\ Relations Hewlett-Packard Enterprise
}

\author{
Grace Crunican* \\ (TE 2022) \\ Retired
}

Donna DeMartino (TE 202I)

General Manager \& CEO

San Joaquin Regional Transit District

Nuria Fernandez* (TE 2020)

General Manager \& CEO

Santa Clara Valley

Transportation Authority (VTA)

John Flaherty (TE 2020)

Senior Fellow

Silicon Valley American

Leadership Form

Rose Guilbault (TE 2020)

Board Member

Peninsula Corridor

Joint Powers Board

Ian Jefferies (Ex-Officio)

President \& CEO

Association of American Railroads

Diane Woodend Jones

(TE 2022)

Principal \& Chair of Board

Lea + Elliott, Inc.
Therese McMillan

(TE 2022)

Executive Director

Metropolitan Transportation

Commission (MTC)

Bradley Mims (TE 2020)

President \& CEO

Conference of Minority

Transportation Officials (COMTO)

Jeff Morales (TE 2022)

Managing Principal

InfraStrategies, LLC

Dan Moshavi, PhD

(Ex-Officio)

Dean, Lucas College and

Graduate School of Business

San José State University

Takayoshi Oshima (TE 202 I)

Chairman \& CEO

Allied Telesis, Inc.

Toks Omishakin

(Ex-Officio)

Director

California Department of

Transportation (Caltrans)
Paul Skoutelas (Ex-Officio)

President \& CEO

American Public Transportation

Association (APTA)

Dan Smith (TE 2020)

President

Capstone Financial Group, Inc.

Beverley Swaim-Staley (TE 2022)

President

Union Station Redevelopment

Corporation

\section{Jim Tymon (Ex-Officio)}

Executive Director

American Association of

State Highway and Transportation

Officials (AASHTO)

\section{Larry Willis (Ex-Officio)}

President

Transportation Trades

Dept., AFL-CIO

$(\mathrm{TE})=$ Term Expiration

* = Past Chair, Board of Trustees

\section{Directors}

Karen Philbrick, Ph.D.

Executive Director

Hilary Nixon, Ph.D.

Deputy Executive Director

\section{Asha Weinstein Agrawal,}

\section{Ph.D.}

Education Director

National Transportation Finance

Center Director

\section{Brian Michael Jenkins}

National Transportation Security

Center Director

\title{
Research Associates Policy Oversight Committee
}

Jan Botha, Ph.D.

Civil \& Environmental Engineering

San José State University

Katherine Kao Cushing,

\section{Ph.D.}

Enviromental Science

San José State University

Dave Czerwinski, Ph.D. Marketing and Decision Science San José State University
Frances Edwards,

Ph.D.

Political Science

San José State University

Taeho Park, Ph.D.

Organization and Management

San José State University

\section{Christa Bailey}

Martin Luther King, Jr. Library

San José State University

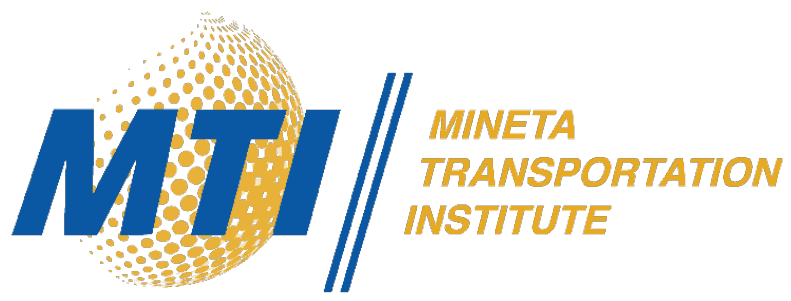

